\title{
Clinical utility of pretreatment prediction of chemoradiotherapy response in rectal cancer: a review
}

\author{
Byong Chul Yoo ${ }^{1} \cdot$ Seung-Gu Yeo ${ }^{2}$ (D)
}

Received: 28 December 2016 / Accepted: 2 February 2017 /Published online: 3 March 2017

(C) European Association for Predictive, Preventive and Personalised Medicine (EPMA) 2017

\begin{abstract}
Approximately 20\% of all patients with locally advanced rectal cancer experience pathologically complete responses following neoadjuvant chemoradiotherapy (CRT) and standard surgery. The utility of radical surgery for patients exhibiting good CRT responses has been challenged. Organsparing strategies for selected patients exhibiting complete clinical responses include local excision or no immediate surgery. The subjects of this tailored management are patients whose presenting disease corresponds to current indications of neoadjuvant CRT, and their post-CRT tumor response is assessed by clinical and radiological examinations. However, a model predictive of the CRT response, applied before any treatment commenced, would be valuable to facilitate such a personalized approach. This would increase organ preservation, particularly in patients for whom upfront CRT is not generally prescribed. Molecular biomarkers hold the greatest promise for development of a pretreatment predictive model of CRT response. A combination of clinicopathological, radiological, and molecular markers will be necessary to render the model robust. Molecular research will also contribute to the development of drugs that can overcome the radioresistance of rectal tumors. Current treatments for rectal cancer are based on the expected prognosis given the presenting disease extent. In the future, treatment schemes may be modified by including the predicted CRT response evaluated at presentation.
\end{abstract}

Seung-Gu Yeo

md6630@schmc.ac.kr

1 Colorectal Cancer Branch, Research Institute, National Cancer Center, Goyang, Republic of Korea

2 Department of Radiation Oncology, Soonchunhyang University College of Medicine, Soonchunhyang University Hospital, 31, Soonchunhyang 6-gil, Cheonan 31151, Republic of Korea
Keywords Rectal cancer · Chemoradiotherapy · Response · Prediction $\cdot$ Wait and see $\cdot$ Watch and wait $\cdot$ Non-operative

\section{Background}

Personalized treatment has become a major topic in oncology $[1,2]$. Currently, two conflicting views are held on the tailored management of locally advanced rectal cancer (LARC, stage II or III). The first restricts the use of radiotherapy [3, 4]. The second prescribes either no surgery or conservative surgery following neoadjuvant chemoradiotherapy (nCRT) [5-9]. The latter approach is more liberal in terms of radiotherapy than the first, but the common goal is to reduce treatment morbidity and improve functional outcomes. The first approach reduces radiation toxicities; the second, surgical sequelae. Surgery has long been the only option for cure of rectal cancer, but is also the principal contributor to post-treatment mortality and morbidity [10-12]. Therefore, the second approach can be more effective in reducing treatment associated morbidity and is the focus of this review.

\section{Role of radiotherapy in rectal cancer}

Standard multimodal management of LARC involves nCRT, radical surgery with total mesorectal excision (TME), and adjuvant chemotherapy $[13,14]$. Inclusion of TME as the standard surgery has remarkably improved rectal cancer control $[15,16]$. However, $\mathrm{nCRT}$ is still effective in dealing with small but devastating inadequacies in TME. In other words, neoadjuvant radiotherapy significantly reduces the local recurrence risk post-TME [17, 18]. Radiotherapy is a core modality of CRT, and the efficacy of radiation is enhanced by concurrent fluoropyrimidine-based chemotherapy $[19,20]$. 
Tumor responses to CRT are revealed by pathological examination of surgical specimens. The extent of response is expressed in various ways, including $\mathrm{T}$ or $\mathrm{N}$ down-classification, downstaging, tumor regression grade, or development of a pathologically complete response (pCR) [21]. Approximately $20 \%$ of patients experience pCR [22]. The tumor is surgically removed irrespective of the CRT response, however the long-term oncological outcomes of those with favorable CRT responses are better [22, 23]. The CRT response is thus a strong prognostic indicator.

\section{Conservative surgery}

TME involves removal of an entire circumferential envelope of perirectal tissue and significantly reduces the local recurrence rate compared with that of the historical blunt dissection [15, 16]. However, various perioperative complications are encountered, including infection, pelvic sepsis, vascular or ureteral injury, anastomotic leakage, and wound complications [9]. The mortality rate is at least $2 \%$ even in fit patients, and over one third of patients report some degree of fecal incontinence and urological or sexual dysfunction [9, 24]. Some 10-30\% of patients require permanent colostomies, with associated significant physical and psychological sequelae [25].

The suggestion that no or conservative post-nCRT surgery might sometimes be appropriate began with the observation that some patients exhibit pCR or near-pCR after nCRT [22]. If nCRT eradicates all tumor cells, radical surgery unnecessarily resects normal tissues, causing various morbidities. Conservative surgery includes transanal local excision and transanal endoscopic microsurgery. Local excision has the advantages of rapid postoperative recovery, no need for a permanent colostomy, and the absence of many morbidities associated with the radical operation [5-7]. This procedure removes only the primary mural tumor, leaving behind most mesorectal lymph nodes. If metastatic tumor cells exist in the lymph nodes, CRT regresses them, along with the primary tumor cells [26-28]. Therefore, management subsequent to local excision is based on the ypT stage: close observation for those of ypT0-1 without unfavorable prognostic factors, but re-operation (TME) for others [5-7].

\section{No surgery}

Dr. Angelita Habr-Gama, a colorectal surgeon from Brazil, pioneered the wait-and-see or watch-and-wait approach for rectal cancer patients [29-31]. This policy, which is also called non-operative management or no immediate surgery, is indicated for selected patients who show a clinical complete response (cCR) post-nCRT. Deferred surgery for a subgroup due to some limitations in cCR judgment has been reported not to compromise long-term oncological outcomes [32].

Habr-Gama et al. conducted a series of studies in which patients with principally $\mathrm{T} 3$ or $\mathrm{N} 1 \mathrm{mid} /$ low rectal tumors, who exhibited post-nCRT cCR, underwent close surveillance only [30-34]. The latest report found that this non-operative approach afforded a 5-year rate of local recurrence "not amenable to salvage" as low as $6 \%[33,34]$. Early tumor regrowth (within 12 months) was apparent in $19 \%$ of patients; however, $94 \%$ underwent salvage surgery with a $75 \%$ sphincter preservation rate. After $>12$ months post-nCRT, an additional $11 \%$ of patients exhibited local recurrence, but $91 \%$ underwent salvage surgery with sphincter preservation in 35\%. The 3year disease-free and overall survival rates were 78 and $88 \%$, respectively, thus comparable to those after the standard regimen (nCRT and TME).

This non-operative approach is under investigation at multiple sites worldwide [35-37]. In the UK, 129 patients with cCR were thus managed [37]. At a median follow-up of 33 months, 44 (34\%) exhibited local regrowth (3-year actuarial rate, $38 \%)$. Thirty-six $(88 \%)$ of 41 patients with nonmetastatic local regrowth were salvaged. On propensity score-matched analysis (109 patients in each group), the 3year non-regrowth disease-free survival did not differ between the watch-and-wait and surgical resection groups (88 vs. $78 \%$ ). Similarly, the 3-year overall survival did not differ (96 vs. $87 \%$ ). In contrast, the watch-and-wait group exhibited significantly better 3-year colostomy-free survival than did the surgical group (74 vs 47\%). It was concluded that a substantial proportion of rectal cancer patients managed by the watchand-wait approach avoided major surgery and averted permanent colostomy without any loss of oncological safety to 3 years.

\section{Prediction of CRT response}

The term "CRT response prediction" has been used indiscriminately in two different situations [38, 39]. One is prediction of the pathological CRT response after CRT completion but before surgery, and the other is prediction of the CRT response before any treatment is given. The former case is actually clinical evaluation or assessment of postCRT tumor status (re-staging), rather than prediction. This assessment is used to select patients for whom conservative or no surgery is appropriate among those in whom the tumor extent at presentation corresponds with the acceptable indications for nCRT. The current indication for $\mathrm{nCRT}$ is LARC, although the argument has been made that patients with relatively low-risk LARCs, such as cT3N0 cancers or upper rectal cancers, do not need to undergo nCRT [4, 40, 41]. Clinical examinations, including endoscopic findings and 
digital rectal evaluations, and radiological studies, play major roles in such evaluation [35-37, 42].

"Pretreatment" CRT prediction has a different value. LARC is associated with an average pCR rate of $20 \%$ [22]. This may be higher in those with early stage rectal cancers considering their low tumor burden. In a pooled data analysis, an association between the clinical T stage and the probability of achieving pCR was apparent: the pCR rates were $58 \%$ (7/12), 28\% (41/145), 16\% (374/2301), and 12\% (40/327) for patients with tumors of clinical stages T1, T2, T3, and T4, respectively [43]. The probability of a cure upon nonoperative management may be higher in patients with early stage tumors. However, upfront CRT constitutes overtreatment in some patients who require deferred radical surgery because surgery alone is the standard regimen for such patients [44]. If alternative initial regimens are to be offered to such patients, the ability to predict CRT response at presentation must be highly sensitive and specific.

\section{Predictive markers}

\section{Clinicopathological factors}

Clinicopathological factors associated with the CRT response to rectal cancer include the levels of serum carcinoembryonic antigen (CEA), carbohydrate antigen 19-9, and fibrinogen; the histological grade and mucinous histology; tumor size, volume, circumference, and movability; the hemoglobin level and blood lymphocyte counts; the clinical T or N stage; and the distance from the tumor to the anal verge [21, 45-57]. Of these factors, the serum CEA level has been the most relevant [48-50]. However, not only the pre-CRT CEA level but also the post-CRT CEA level, and/or the change in the CEA pattern after CRT, are often analyzed together. The latter two measures are more closely related to the pathological CRT response than is the pre-CRT CEA level [58-60]. This is not surprising because the latter values reflect the degree of CRT response. The performance of a predictive model would be enhanced using data obtained during or after CRT, but a pretreatment prediction must be based on only pretreatment measurements.

A few nomograms using clinicopathological factors have been developed. However, the endpoint was the long-term oncological outcome with the aim of selecting candidates for adjuvant chemotherapy [61]. The variables used in analysis included treatment factors and the ypStage. The endpoint of other nomograms was the post-nCRT ypN status [62, 63]. Both pre-nCRT parameters and post-surgery pathological factors were used to construct the nomograms. The purpose was to predict nodal status after nCRT and local excision, during which mesorectal lymph nodes cannot be pathologically examined.

\section{Radiological markers}

The apparent diffusion coefficient (ADC) measured via diffusion-weighted magnetic resonance imaging is a typical radiological marker of the CRT response of rectal cancer. As the tumors are highly cellular, water diffusion is restricted. ADC quantifies such restriction diffusion [64]. Low preCRT ADC values and large post-CRT increases in such values correlate with a good pathological response [64]. Compared with the pre-CRT ADC values, the post-CRT ADCs and the CRT-induced ADC changes were more predictive of CRT response [64-66].

Another type of functional imaging is positron emission tomography (PET). ${ }^{18}$ Fluorodeoxyglucose PET-computed tomography detects and quantifies increases in glucose metabolism within cancer cells [67]. Rather than the pre-CRT standardized uptake value (SUV), changes in the SUV early in, or after, CRT correlate with the CRT response [67-69].

A combination of data from both imaging modalities, the pre-CRT ADC and the SUV change during CRT, improved the predictive specificity of the CRT response [70, 71]. A nomogram combining clinical factors (the clinical $\mathrm{T}$ and $\mathrm{N}$ stages) and PET parameters was used to predict pCR [72]. However, the PET parameters utilized were the changes in

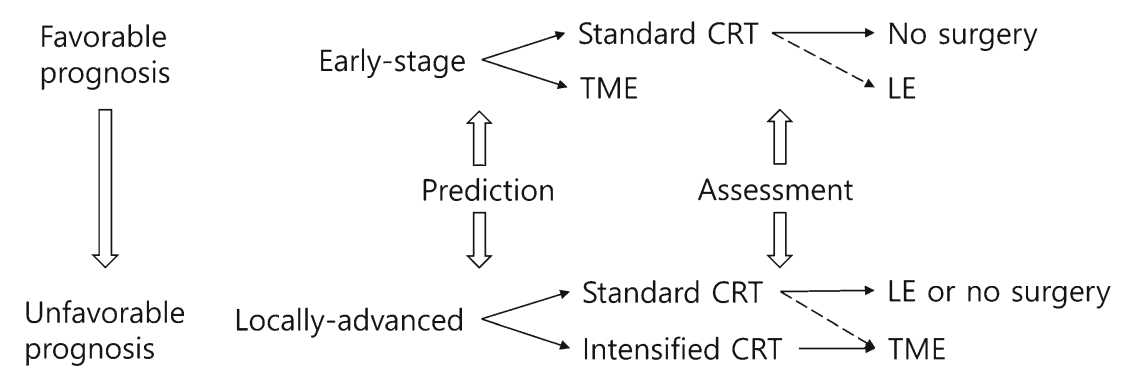

Fig. 1 Suggested treatment scheme for rectal cancer when a robust pretreatment predictive model is available. Among both early stage and locally advanced patients, those predicted to exhibit favorable responses undergo standard CRT. Management decisions after CRT are aided by assessment of post-CRT tumor status. As the performance of the pretreatment predictive model improves, LE (for early-stage patients) and TME (for locally advanced patients) after standard CRT will become increasingly unnecessary (dotted lines). The treatment regimens are arranged from top to bottom according to prognosis. CRT chemoradiotherapy, TME total mesorectal excision, $L E$ local excision 
the $\mathrm{SUV}_{\text {mean }}$ and maximal tumor diameter during CRT. No nomogram using only pretreatment clinicopathological and/or radiological data is yet available to predict the CRT response in rectal cancer patients.

\section{Molecular markers}

Molecular biomarkers predictive of the CRT response of rectal cancer include p53, KRAS, the epidermal growth factor receptor, vascular endothelial growth factor, Bcl-2, and Bax [73-76]. These proteins are involved in DNA damage repair, cell proliferation, angiogenesis, and apoptosis. Biomarkers of emerging interest include those associated with the epithelialto-mesenchymal transition and microsatellite instability [77]. The gene or microRNA expression profiling using microarray has been used to analyze hundreds of potential biomarkers and to select promising candidates [77, 78]. Analyses of circulating tumor cells or circulating tumor nucleic acids have also identified potential predictive markers [79, 80]. Although the several drawbacks include poor reproducibility and lack of prospective independent validation, molecular markers have the greatest future potential.

Incorporation of blood biomarkers enhanced the accuracy of earlier predictive models using only clinical variables and PET data. A model combining blood biomarkers (interleukin6, interleukin-8, osteopontin, CEA); clinical factors (tumor length, clinical $\mathrm{T}$ and $\mathrm{N}$ stage); and the pretreatment $\mathrm{SUV}_{\text {max }}$, had areas under the curve of 0.81 for $\mathrm{pCR}$ and 0.78 for downstaging [81]. Data derived using this model were used to build a nomogram, which has not yet been externally validated. To date, no pretreatment predictive model is sufficiently robust to be of clinical utility.

\section{Future perspectives}

Rectal cancer is an excellent candidate for personalized multimodal treatment. About $20 \%$ of those with LARC, and probably a higher percentage of early stage rectal cancer patients, could achieve complete tumor regression when given upfront CRT. No surgery or conservative surgery is a valuable treatment option, particularly for those at high risk of complications following major surgery (the elderly or those with comorbidities) and those reluctant to sacrifice the anus.

Current treatment schemes for rectal cancer are based on the expected prognosis considering the extent of presenting disease. Such schemes may be further divided with additional reference to the CRT response predicted at presentation. Figure 1 illustrates a possible future treatment scheme. In cases for whom nCRT is prescribed because their disease burden at presentation so indicates, post-nCRT tumor status could be assessed via clinical and radiological examinations. A predictive model that includes molecular markers may not be of great clinical utility at this point in time. Predictive modeling may be more valuable for those for whom nCRT is not usually indicated, expanding the opportunities to preserve organs. Such a model could also be used to identify molecular markers of, and/or the pathways responsible for, radioresistance, and to develop novel drugs overcoming such radioresistance. Such agents could be added to the CRT for LARC patients predicted to exhibit poor responses to standard CRT.

Many searches for factors predictive of CRT response have used not only pre-CRT but also peri- and/or post-CRT values. The latter two values are statistically more relevant because they reflect the response to CRT. However, it would be better to use only pretreatment factors when constructing a predictive model. Such a model would be more useful in clinical practice.

A combination of many variables including clinical, pathological, imaging, proteomic, and genomic factors, and blood biomarkers, is required to develop a robust pretreatment predictive model. Different tumor behaviors are likely attributable to the many interactions among multiple factors. This renders simple monocentric analysis statistically challenging. Progress in automated data-mining and machine learning may help unravel the complex non-linear interactions among multiple variables and the CRT responses of rectal tumors [82].

\section{Conclusions}

A paradigm shift has occurred in terms of the use of CRT to treat rectal cancer. First, the adjuvant CRT for LARC has changed to nCRT. Second, universal radical surgery after nCRT has changed to include response-based choices that preserve organs and reduce morbidity. In the future, a pretreatment predictive model may further expand the role played by CRT as the primary treatment for rectal cancer.

Acknowledgements This work was supported by grants from the National Cancer Center in Korea (1710040-1) and the Soonchunhyang University Research Fund.

\section{Compliance with ethical standards}

Competing interests The authors declare that they have no competing interests.References

1. Golubnitschaja O, Baban B, Boniolo G, Wang W, Bubnov R, Kapalla M, et al. Medicine in the early twenty-first century: paradigm and anticipation-EPMA position paper 2016. EPMA J. 2016;7:23. 
2. Grech G, Zhan X, Yoo BC, Bubnov R, Hagan S, Danesi R, et al. EPMA position paper in cancer: current overview and future perspectives. EPMA J. 2015;6:9.

3. Taylor FG, Quirke P, Heald RJ, Moran B, Blomqvist L, Swift I, et al. Preoperative high-resolution magnetic resonance imaging can identify good prognosis stage I, II, and III rectal cancer best managed by surgery alone: a prospective, multicenter, European study. Ann Surg. 2011;253:711-9.

4. Joye I, Haustermans K. Which patients with rectal cancer do not need radiotherapy? Semin Radiat Oncol. 2016;26:199-204.

5. Yeo SG, Kim DY, Kim TH, Kim SY, Chang HJ, Park JW, et al. Local excision following pre-operative chemoradiotherapy-induced downstaging for selected cT3 distal rectal cancer. Jpn J Clin Oncol. 2010;40:754-60.

6. Yeo SG. Preoperative chemoradiotherapy followed by transanal local excision for T3 distal rectal cancer: a case report. Exp Ther Med. 2016;11:1465-8.

7. Shin YS, Yoon YS, Lim SB, Yu CS, Kim TW, Chang HM, et al. Preoperative chemoradiotherapy followed by local excision in clinical T2N0 rectal cancer. Radiat Oncol J. 2016;34:177-85.

8. Yeo SG, Kim DY, Oh JH. Long-term survival without surgery following a complete response to pre-operative chemoradiotherapy for rectal cancer: a case series. Oncol Lett. 2013;6:1573-6.

9. Kim MJ, Kim ES, Yeo SG. Definitive high-dose radiotherapy with concurrent chemotherapy for locally advanced rectal cancer: a case report and literature review. Medicine (Baltimore). 2016;95:e5059.

10. Peeters KC, van de Velde CJ, Leer JW, Martijn H, Junggeburt JM, Kranenbarg EK, et al. Late side effects of short-course preoperative radiotherapy combined with total mesorectal excision for rectal cancer: increased bowel dysfunction in irradiated patients - a Dutch colorectal cancer group study. J Clin Oncol. 2005;23:6199-206.

11. Lange MM, Maas CP, Marijnen CA, Wiggers T, Rutten HJ, Kranenbarg EK, et al. Urinary dysfunction after rectal cancer treatment is mainly caused by surgery. Br J Surg. 2008;95:1020-8.

12. Milgrom SA, Goodman KA, Nash GM, Paty PB, Guillem JG, Temple LK, et al. Neoadjuvant radiation therapy prior to total mesorectal excision for rectal cancer is not associated with postoperative complications using current techniques. Ann Surg Oncol. 2014;21:2295-302.

13. Sauer R, Becker H, Hohenberger W, Rodel C, Wittekind C, Fietkau $\mathrm{R}$, et al. Preoperative versus postoperative chemoradiotherapy for rectal cancer. N Engl J Med. 2004;351:1731-40.

14. Sauer R, Liersch T, Merkel S, Fietkau R, Hohenberger W, Hess C, et al. Preoperative versus postoperative chemoradiotherapy for locally advanced rectal cancer: results of the German CAO/ARO/ AIO-94 randomized phase III trial after a median follow-up of 11 years. J Clin Oncol. 2012;30:1926-33.

15. Heald RJ, Moran BJ, Ryall RD, Sexton R, MacFarlane JK. Rectal cancer: the Basingstoke experience of total mesorectal excision, 1978-1997. Arch Surg. 1998;133:894-9.

16. Maurer CA, Renzulli P, Kull C, Kaser SA, Mazzucchelli L, Ulrich $\mathrm{A}$, et al. The impact of the introduction of total mesorectal excision on local recurrence rate and survival in rectal cancer: long-term results. Ann Surg Oncol. 2011;18:1899-906.

17. Kapiteijn E, Marijnen CA, Nagtegaal ID, Putter H, Steup WH, Wiggers T, et al. Preoperative radiotherapy combined with total mesorectal excision for resectable rectal cancer. $\mathrm{N}$ Engl J Med. 2001;345:638-46.

18. van Gijn W, Marijnen CA, Nagtegaal ID, Kranenbarg EM, Putter $\mathrm{H}$, Wiggers $\mathrm{T}$, et al. Preoperative radiotherapy combined with total mesorectal excision for resectable rectal cancer: 12-year follow-up of the multicentre, randomised controlled TME trial. Lancet Oncol. 2011;12:575-82.

19. Bosset JF, Collette L, Calais G, Mineur L, Maingon P, RadosevicJelic L, et al. Chemotherapy with preoperative radiotherapy in rectal cancer. N Engl J Med. 2006;355:1114-23.
20. De Caluwe L, Van Nieuwenhove Y, Ceelen WP. Preoperative chemoradiation versus radiation alone for stage II and III resectable rectal cancer. Cochrane Database Syst Rev. 2013;2:CD006041.

21. Yeo SG, Kim DY, Kim TH, Jung KH, Hong YS, Chang HJ, et al. Tumor volume reduction rate measured by magnetic resonance volumetry correlated with pathologic tumor response of preoperative chemoradiotherapy for rectal cancer. Int J Radiat Oncol Biol Phys. 2010;78:164-71.

22. Yeo SG, Kim DY, Kim TH, Chang HJ, Oh JH, Park W, et al. Pathologic complete response of primary tumor following preoperative chemoradiotherapy for locally advanced rectal cancer: longterm outcomes and prognostic significance of pathologic nodal status (KROG 09-01). Ann Surg. 2010;252:998-1004.

23. Yeo SG, Kim DY, Park JW, Choi HS, Oh JH, Kim SY, et al. Stageto-stage comparison of preoperative and postoperative chemoradiotherapy for T3 mid or distal rectal cancer. Int J Radiat Oncol Biol Phys. 2012;82:856-62.

24. Pozo ME, Fang SH. Watch and wait approach to rectal cancer: a review. World J Gastrointest Surg. 2015;7:306-12.

25. Camilleri-Brennan J, Steele RJ. Objective assessment of morbidity and quality of life after surgery for low rectal cancer. Colorectal Dis. 2002;4:61-6.

26. Read TE, Andujar JE, Caushaj PF, Johnston DR, Dietz DW, Myerson RJ, et al. Neoadjuvant therapy for rectal cancer: histologic response of the primary tumor predicts nodal status. Dis Colon Rectum. 2004;47:825-31.

27. Pucciarelli S, Capirci C, Emanuele U, Toppan P, Friso ML, Pennelli GM, et al. Relationship between pathologic T-stage and nodal metastasis after preoperative chemoradiotherapy for locally advanced rectal cancer. Ann Surg Oncol. 2005;12:111-6.

28. Kim DW, Kim DY, Kim TH, Jung KH, Chang HJ, Sohn DK, et al. Is T classification still correlated with lymph node status after preoperative chemoradiotherapy for rectal cancer? Cancer. 2006;106:1694-700.

29. Beets GL, Figueiredo NL, Habr-Gama A, van de Velde CJ. A new paradigm for rectal cancer: Organ preservation: Introducing the International Watch \& Wait Database (IWWD). Eur J Surg Oncol. 2015;41:1562-4.

30. Habr-Gama A, Perez RO, Sao Juliao GP, Proscurshim I, GamaRodrigues J. Nonoperative approaches to rectal cancer: a critical evaluation. Semin Radiat Oncol. 2011;21:234-9.

31. Habr-Gama A, Perez RO, Nadalin W, Sabbaga J, Ribeiro Jr U. Silva e Sousa AH, Jr. et al. Operative versus nonoperative treatment for stage 0 distal rectal cancer following chemoradiation therapy: longterm results. Ann Surg. 2004;240:711-7. discussion 7-8.

32. Habr-Gama A, Perez RO, Proscurshim I, Nunes Dos Santos RM, Kiss D, Gama-Rodrigues J, et al. Interval between surgery and neoadjuvant chemoradiation therapy for distal rectal cancer: does delayed surgery have an impact on outcome? Int J Radiat Oncol Biol Phys. 2008;71:1181-8.

33. Habr-Gama A, Sao Juliao GP, Perez RO. Nonoperative management of rectal cancer: identifying the ideal patients. Hematol Oncol Clin North Am. 2015;29:135-51.

34. Habr-Gama A, Gama-Rodrigues J, Sao Juliao GP, Proscurshim I, Sabbagh C, Lynn PB, et al. Local recurrence after complete clinical response and watch and wait in rectal cancer after neoadjuvant chemoradiation: impact of salvage therapy on local disease control. Int J Radiat Oncol Biol Phys. 2014;88:822-8.

35. Maas M, Beets-Tan RG, Lambregts DM, Lammering G, Nelemans PJ, Engelen SM, et al. Wait-and-see policy for clinical complete responders after chemoradiation for rectal cancer. J Clin Oncol. 2011;29:4633-40.

36. Smith JD, Ruby JA, Goodman KA, Saltz LB, Guillem JG, Weiser $\mathrm{MR}$, et al. Nonoperative management of rectal cancer with complete clinical response after neoadjuvant therapy. Ann Surg. 2012;256:965-72. 
37. Renehan AG, Malcomson L, Emsley R, Gollins S, Maw A, Myint AS, et al. Watch-and-wait approach versus surgical resection after chemoradiotherapy for patients with rectal cancer (the OnCoRe project): a propensity-score matched cohort analysis. Lancet Oncol. 2016;17:174-83.

38. Zeestraten EC, Kuppen PJ, van de Velde CJ, Marijnen CA. Prediction in rectal cancer. Semin Radiat Oncol. 2012;22:175-83.

39. Goodman KA. Definitive chemoradiotherapy ("Watch-and-Wait" approach). Semin Radiat Oncol. 2016;26:205-10.

40. Wo JY, Mamon HJ, Ryan DP, Hong TS. T3N0 rectal cancer: radiation for all? Semin Radiat Oncol. 2011;21:212-9.

41. Chan E, Wise PE, Chakravarthy AB. Controversies in radiation for upper rectal cancers. J Natl Compr Canc Netw. 2012;10:1567-72.

42. Habr-Gama A, Perez RO, Wynn G, Marks J, Kessler H, GamaRodrigues J. Complete clinical response after neoadjuvant chemoradiation therapy for distal rectal cancer: characterization of clinical and endoscopic findings for standardization. Dis Colon Rectum. 2010;53:1692-8.

43. Maas M, Nelemans PJ, Valentini V, Das P, Rodel C, Kuo LJ, et al. Long-term outcome in patients with a pathological complete response after chemoradiation for rectal cancer: a pooled analysis of individual patient data. Lancet Oncol. 2010;11:835-44.

44. Valentini V, Aristei C, Glimelius B, Minsky BD, Beets-Tan R, Borras JM, et al. Multidisciplinary Rectal Cancer Management: 2nd European Rectal Cancer Consensus Conference (EURECACC2). Radiother Oncol. 2009;92:148-63.

45. Yeo SG, Kim DY, Kim TH, Kim SY, Baek JY, Chang HJ, et al. Carbohydrate antigen 19-9 levels associated with pathological responses to preoperative chemoradiotherapy in rectal cancer. Asian Pac J Cancer Prev. 2014;15:5383-7.

46. Lee JH, Hyun JH, Kim DY, Yoo BC, Park JW, Kim SY, et al. The role of fibrinogen as a predictor in preoperative chemoradiation for rectal cancer. Ann Surg Oncol. 2015;22:209-15.

47. McCawley N, Clancy C, O'Neill BD, Deasy J, McNamara DA, Burke JP. Mucinous rectal adenocarcinoma is associated with a poor response to neoadjuvant chemoradiotherapy: a systematic review and meta-analysis. Dis Colon Rectum. 2016;59:1200-8.

48. Yeo SG, Kim DY, Chang HJ, Park JW, Oh JH, Kim BC, et al. Reappraisal of pretreatment carcinoembryonic antigen in patients with rectal cancer receiving preoperative chemoradiotherapy. Tumori. 2013;99:93-9.

49. Yeo SG. Association of pretreatment serum carcinoembryonic antigen levels with chemoradiation-induced downstaging and downsizing of rectal cancer. Mol Clin Oncol. 2016;4:631-5.

50. Probst CP, Becerra AZ, Aquina CT, Tejani MA, Hensley BJ, Gonzalez MG, et al. Watch and Wait? - elevated pretreatment CEA is associated with decreased pathological complete response in rectal cancer. J Gastrointest Surg. 2016;20:43-52.

51. Yeo SG, Kim DY. An update on preoperative radiotherapy for locally advanced rectal cancer. J Korean Soc Coloproctol. 2012;28:179-87.

52. Patel SV, Roxburgh CS, Vakiani E, Shia J, Smith JJ, Temple LK, et al. Distance to the anal verge is associated with pathologic complete response to neoadjuvant therapy in locally advanced rectal cancer. J Surg Oncol. 2016;114:637-41.

53. Heo J, Chun M, Noh OK, Oh YT, Suh KW, Park JE, et al. Sustaining blood lymphocyte count during preoperative chemoradiotherapy as a predictive marker for pathologic complete response in locally advanced rectal cancer. Cancer Res Treat. 2016:48:232-9.

54. Moureau-Zabotto L, Farnault B, de Chaisemartin C, Esterni B, Lelong B, Viret F, et al. Predictive factors of tumor response after neoadjuvant chemoradiation for locally advanced rectal cancer. Int J Radiat Oncol Biol Phys. 2011;80:483-91.

55. Park CH, Kim HC, Cho YB, Yun SH, Lee WY, Park YS, et al. Predicting tumor response after preoperative chemoradiation using clinical parameters in rectal cancer. World J Gastroenterol. 2011;17: 5310-6.
56. Huh JW, Kim HR, Kim YJ. Clinical prediction of pathological complete response after preoperative chemoradiotherapy for rectal cancer. Dis Colon Rectum. 2013;56:698-703.

57. Choi E, Kim JH, Kim OB, Kim MY, Oh YK, Baek SG. Predictors of pathologic complete response after preoperative concurrent chemoradiotherapy of rectal cancer: a single center experience. Radiat Oncol J. 2016;34:106-12.

58. Yang KL, Yang SH, Liang WY, Kuo YJ, Lin JK, Lin TC, et al. Carcinoembryonic antigen (CEA) level, CEA ratio, and treatment outcome of rectal cancer patients receiving pre-operative chemoradiation and surgery. Radiat Oncol. 2013;8:43.

59. Kleiman A, Al-Khamis A, Farsi A, Kezouh A, Vuong T, Gordon $\mathrm{PH}$, et al. Normalization of CEA levels post-neoadjuvant therapy is a strong predictor of pathologic complete response in rectal cancer. J Gastrointest Surg. 2015;19:1106-12.

60. Jang NY, Kang SB, Kim DW, Kim JH, Lee KW, Kim IA, et al. The role of carcinoembryonic antigen after neoadjuvant chemoradiotherapy in patients with rectal cancer. Dis Colon Rectum. 2011;54:245-52.

61. Valentini V, van Stiphout RG, Lammering G, Gambacorta MA, Barba MC, Bebenek M, et al. Nomograms for predicting local recurrence, distant metastases, and overall survival for patients with locally advanced rectal cancer on the basis of European randomized clinical trials. J Clin Oncol. 2011;29:3163-72.

62. Jwa E, Kim JH, Han S, Park JH, Lim SB, Kim JC, et al. Nomogram to predict ypN status after chemoradiation in patients with locally advanced rectal cancer. Br J Cancer. 2014;111:249-54.

63. Newton AD, Li J, Jeganathan AN, Mahmoud NN, Epstein AJ, Paulson EC. A nomogram to predict lymph node positivity following neoadjuvant chemoradiation in locally advanced rectal cancer. Dis Colon Rectum. 2016;59:710-7.

64. Jacobs L, Intven M, van Lelyveld N, Philippens M, Burbach M, Seldenrijk K, et al. Diffusion-weighted MRI for early prediction of treatment response on preoperative chemoradiotherapy for patients with locally advanced rectal cancer: a feasibility study. Ann Surg. 2016;263:522-8.

65. Xie H, Sun T, Chen M, Wang H, Zhou X, Zhang Y, et al. Effectiveness of the apparent diffusion coefficient for predicting the response to chemoradiation therapy in locally advanced rectal cancer: a systematic review and meta-analysis. Medicine (Baltimore). 2015;94:e517.

66. Intven M, Reerink O, Philippens ME. Diffusion-weighted MRI in locally advanced rectal cancer : pathological response prediction after neo-adjuvant radiochemotherapy. Strahlenther Onkol. 2013;189:117-22.

67. Kim JW, Kim HC, Park JW, Park SC, Sohn DK, Choi HS, et al. Predictive value of (18)FDG PET-CT for tumour response in patients with locally advanced rectal cancer treated by preoperative chemoradiotherapy. Int J Colorectal Dis. 2013;28:1217-24.

68. Maffione AM, Chondrogiannis S, Capirci C, Galeotti F, Fornasiero A, Crepaldi G, et al. Early prediction of response by (1)(8)F-FDG $\mathrm{PET} / \mathrm{CT}$ during preoperative therapy in locally advanced rectal cancer: a systematic review. Eur J Surg Oncol. 2014;40:1186-94.

69. Memon S, Lynch AC, Akhurst T, Ngan SY, Warrier SK, Michael $\mathrm{M}$, et al. Systematic review of FDG-PET prediction of complete pathological response and survival in rectal cancer. Ann Surg Oncol. 2014;21:3598-607.

70. Lambrecht M, Deroose C, Roels S, Vandecaveye V, Penninckx F, Sagaert X, et al. The use of FDG-PET/CT and diffusion-weighted magnetic resonance imaging for response prediction before, during and after preoperative chemoradiotherapy for rectal cancer. Acta Oncol. 2010;49:956-63.

71. Joye I, Deroose CM, Vandecaveye V, Haustermans K. The role of diffusion-weighted MRI and (18)F-FDG PET/CT in the prediction of pathologic complete response after radiochemotherapy for rectal cancer: a systematic review. Radiother Oncol. 2014;113:158-65. 
72. van Stiphout RG, Valentini V, Buijsen J, Lammering G, Meldolesi E, van Soest J, et al. Nomogram predicting response after chemoradiotherapy in rectal cancer using sequential PETCT imaging: a multicentric prospective study with external validation. Radiother Oncol. 2014;113:215-22.

73. Hur H, Kim NK, Min BS, Baik SH, Lee KY, Koom WS, et al. Can a biomarker-based scoring system predict pathologic complete response after preoperative chemoradiotherapy for rectal cancer? Dis Colon Rectum. 2014;57:592-601.

74. Grade M, Wolff HA, Gaedcke J, Ghadimi BM. The molecular basis of chemoradiosensitivity in rectal cancer: implications for personalized therapies. Langenbecks Arch Surg. 2012;397:543-55.

75. Yeo SG, Kim DY, Kim KH, Ku JL, Kim JS, Cho MJ, et al. Hydroxymethylglutaryl-coenzyme a synthase 2 expression is associated with chemoradiotherapy responses in colorectal cancer. Dis Colon Rectum. 2012;55:686-94.

76. Kim K, Yeo SG, Yoo BC. Identification of hypoxanthine and phosphoenolpyruvic Acid as serum markers of chemoradiotherapy response in locally advanced rectal cancer. Cancer Res Treat. 2015;47:78-89.

77. Lim SH, Chua W, Henderson C, Ng W, Shin JS, Chantrill L, et al. Predictive and prognostic biomarkers for neoadjuvant chemoradiotherapy in locally advanced rectal cancer. Crit Rev Oncol Hematol. 2015;96:67-80.

78. Akiyoshi T, Kobunai T, Watanabe T. Predicting the response to preoperative radiation or chemoradiation by a microarray analysis of the gene expression profiles in rectal cancer. Surg Today. 2012;42:713-9.

79. Sun W, Li G, Wan J, Zhu J, Shen W, Zhang Z. Circulating tumor cells: a promising marker of predicting tumor response in rectal cancer patients receiving neoadjuvant chemo-radiation therapy. Oncotarget. 2016;7:69507-17.

80. Yu J, Li N, Wang X, Ren H, Wang W, Wang S, et al. Circulating serum microRNA-345 correlates with unfavorable pathological response to preoperative chemoradiotherapy in locally advanced rectal cancer. Oncotarget. 2016;7:64233-43.

81. Buijsen J, van Stiphout RG, Menheere PP, Lammering G, Lambin P. Blood biomarkers are helpful in the prediction of response to chemoradiation in rectal cancer: a prospective, hypothesis driven study on patients with locally advanced rectal cancer. Radiother Oncol. 2014;111:237-42.

82. Meldolesi E, van Soest J, Damiani A, Dekker A, Alitto AR, Campitelli M, et al. Standardized data collection to build prediction models in oncology: a prototype for rectal cancer. Future Oncol. 2016;12:119-36. 